\title{
“Quiero ser el Chapito...”: narrativas de violencia en niños y adolescentes del occidente de México
}

\section{Las labores escolares interrumpidas}

"Quiero ser Chapito Guzmán para tener dinero y ser famoso. El más buscado...". Versa la frase inocente, hasta cierto punto, de un pequeño de 7 años, escrita encima de un dibujo trazado por su mano en una escuela rural del norte de Jalisco (Prieto Quezada, 2011).

En ciertas partes de México, como en algunos recovecos de la Sierra Madre Occidental, los niños dejan de asistir a clases para trabajar por cortas temporadas en la siembra y el cultivo de marihuana (Spiller, 2014). La mayoría de ellos se ausentan de dos a tres semanas (en la época de la cosecha) y cuentan con el apoyo y consentimiento de sus padres, quienes incluso hablan con los profesores y solicitan el permiso para justificar las ausencias. Otros se internan en la Sierra hasta por más de tres meses para ayudar a cuidar los sembradíos de la hierba, sobre todo los que son parientes de algún "narquillo" (2014). Algunos nunca más retomarán sus estudios, seducidos por los ingresos económicos relativamente fáciles. Los frutos que puedan obtener a muy largo plazo de la escuela les resultan inciertos y poco deseables.

$\mathrm{El}$ ingreso que obtienen muchos de estos niños y jóvenes mediante este negocio es el principal recurso económico con que se sostienen sus familias en muchas comunidades de zonas marginadas y olvidadas de 
México. Familias completas emplean a todos sus miembros en dicha labor: desde los más pequeños hasta los abuelos. Unos la siembran, otros la cuidan durante varios meses, otros más la cosechan y luego la limpian, separándole sus flores y capullos, sobre todo las mujeres mayores y los ancianos.

Al pasar cerca de las callejuelas de algunas comunidades perdidas en la Sierra Madre Occidental, no deja de emanar de los zaguanes y corrales de las derruidas casas de adobe el aroma a cannabis fresca (2014).

A los profesores no les queda más remedio que escuchar, mirar, acceder y guardar silencio. En algunos rescoldos de la Sierra Madre Occidental, en décadas anteriores, las parcelas estaban dedicadas a la siembra de maíz, cebada, frijol, chile, etc. Hoy en día, debido al bajo costo con que son compradas las producciones tradicionales de los campesinos, las tierras son empleadas para el cultivo de marihuana. Aunque el precio de la hierba haya caído casi un $70 \%$ en los últimos años, debido a la competencia encarnizada de los grupos o carteles por controlar su producción y comercio, así como al ingreso a los mercados de estupefacientes, de nuevas drogas artificiales producidas en laboratorios clandestinos (2014). A pesar de los riesgos, este tipo de cultivo es un poco más rentable que las antiguas producciones de las que vivían los campesinos en ciertas zonas de México desde épocas ancestrales (2014).

Los riesgos son demasiados, en la última década mucha gente relacionada con este negocio ha muerto o desaparecido. No deja de llamar la atención que buena parte de las víctimas son niños y jóvenes, quienes al estar involucrados directa o indirectamente con el negocio y los conflictos derivados de él, son los que más sufren sus consecuencias.

Varias organizaciones mundiales señalaron a México como uno de los países más violentos y peligrosos, debido a los hechos presenciados en los últimos años, donde una serie de sucesos conmocionaron al país completo, en especial por los asesinatos masivos que desde el 2006 se presentan en todo el país.

De los más recientes, se tiene el presentado el 13 de mayo de 2012: los cuerpos de 49 personas fueron encontrados en Cadereyta Jiménez. Sus restos fueron dejados a lo largo de la carretera en Nuevo León, entre las ciudades de Monterrey y Reynosa, Tamaulipas. En el mismo mes, el 9 de mayo, los restos de 18 cadáveres fueron hallados dentro 
de dos camiones cerca de Chapala, Jalisco, justo al sureste de la ciudad de Guadalajara.

Otro no menos cruel fue el evento que se dio en la ciudad de Monterrey, en donde murieron alrededor de 53 personas en un ataque al Casino Royal que provocó un gran incendio y conmoción a la población y donde se presumió también que un cartel del narcotráfico había sido el responsable del ataque.

Con la información de las instancias de seguridad pública y de procuración de justicia de los Estados, se puede afirmar que en México el número de muertos hasta el 2011, de guerra calderonista contra el narcotráfico, ya superó los 60.000, cifra escalofriante en la que figuran presuntos delincuentes, sicarios, policías, soldados, marinos y civiles — “daños colaterales”, según el Gobierno federal—y más recientemente, defensores de los derechos humanos.

En México, la violencia parece ser un fenómeno cotidiano, que se ha manifestado con gran intensidad durante la última década. La violencia como objeto de estudio también ha ido configurándose en los últimos años desde diferentes ámbitos teóricos y prácticos; desde el derecho, la psicología, la sociología, la filosofía y la pedagogía. Puede afirmarse que en años recientes hubo un cambio teórico-práctico en la conceptualización y la acción para explicar la violencia de los últimos años.

La naturalización de la violencia en México tiene como principales víctimas a las poblaciones más vulnerables: niños y jóvenes (también mujeres). La violencia entra en ellos a través del discurso, producido por los medios de comunicación dominantes, pero también por medio de los adultos, quienes los rodean y son modelos de vida para ellos. La violencia no solo es verbal, acaba colándose en sus palabras y siendo parte de su ser. Finalmente, los niños y jóvenes son partícipes y víctimas de ella.

\section{Discursos de violencia con que se embeben los jóvenes mexicanos}

Los discursos de la violencia no solo son verbales, están constituidos por elementos de significados que van más allá de las palabras. Utilizan 
la imagen, el sonido, las emociones y el movimiento para transmitir sus contenidos agresivos y llegar a los aparatos perceptuales de los miembros más jóvenes de la sociedad.

Los videos musicales más populares poseen imágenes sexuales y plenas de lujos inalcanzables que los niños y jóvenes no pueden poseer o a los que jamás tendrán acceso en su realidad: mujeres exuberantes con sendos escotes, vehículos lujosos, armas, casas residenciales, equipos telefónicos inteligentes, videojuegos de última generación, whisky y bebidas alcohólicas de marcas y precios ostentosos, fama y popularidad. Todo ello es parte del alimento psicológico diario que digieren sin ningún filtro moral, las mentes de los más pequeños. Alimento que a la larga resultará tóxico y venenoso para ellos y su sociedad.

Las letras de las canciones que escuchan se encuentran plenas de agresividad hacia sus compañeros y hacia las chicas de su edad. Presentan como ideales a seguir a sujetos armados o francamente violentos, quienes en varias ocasiones, a través de su música, presumen sus vínculos con el crimen organizado y obtienen la admiración de las muchachas bonitas y, en general, de su comunidad.

Una muestra de ello es la polémica desatada por el cantante de banda Gerardo Ortiz, quien en uno de sus últimos videos musicales comete un feminicidio ficticio, por lo cual varias organizaciones le exigieron una disculpa; al final, el video fue eliminado de internet, por lo menos de los perfiles oficiales del cantante, y se le prohibió presentarse en escenarios de Guadalajara.

Está también el ejemplo de los adultos, padres de familia, vecinos, inclusive tutores y profesores, los cuales se dejan llevar del mismo modo y hasta con mayor frenesí que los chicos y no se quedan atrás en la oportunidad de aparentar encontrarse en "la onda" del discurso que alaba al narco. Presumen lo que en bastantes ocasiones no poseen y transmiten a los niños unos valores donde lo más importante es la apariencia exterior de las cosas, a costa de lo que sea. Regularmente, es gente adulta que no necesariamente tiene vínculos con el crimen organizado y se dedica a actividades comunes, pero escucha de cualquier manera la música dedicada a los narcotraficantes, los imita en su manera de vestir, hablar y conducirse. 
Los medios de comunicación, por una parte, condenan la violencia armada a gran escala y a sus actores, pero, por otra, sugieren a los niños y jóvenes que es el único camino hacia la popularidad, el ascenso social y la felicidad, la cultura del dinero fácil y el ingreso a las filas de grupos delincuenciales.

Todo en la cultura popular de moda, o una parte muy importante de ella, la cual circula libremente en Internet y en redes sociales, incluso ahora en la televisión de manera más abierta, invita a los muchachos a seguir como ideales de vida a los sujetos que obtienen dinero rápido y fácil a través de medios ilícitos. A tal grado que, en algunos contextos de México, el ideal de vida del narco o del criminal es el único modelo a seguir o el más tentador y sencillo por parte de niños y jóvenes.

Está también la reducción del papel de las chicas a un cliché o imagen estereotipada: la presentación de la mujer delgada, casi flaca, pero con sus partes íntimas operadas para resultar más atractiva a los hombres que practican la violencia. Esto resulta en una agresión hacia el cuerpo de la mujer y hacia las posibilidades de desarrollo pleno del género femenino.

\section{La zona norte de Jalisco y sur de Zacatecas}

La zona norte de Jalisco y sur de Zacatecas desde hace muchas décadas ha sido lastimada por la pobreza, la marginación y el olvido, condenada por el diario ejercicio de las políticas públicas del Gobierno y del país.

La región norte de Jalisco constituye una de las zonas del Estado con tradiciones culturales enraizadas en su comunidad. Esta zona, enclavada en la Sierra Madre Occidental, tiene una geografía muy pronunciada y un clima semiárido.

Para llegar a ella desde Guadalajara, la capital del Estado, existe un camino accidentado que con dirección norte se adentra hacia Zacatecas antes de regresar a Jalisco, para ingresar por uno de los tres dedos que distinguen su apariencia cartográfica. Últimamente, por esta vía de comunicación, se han presentado asaltos, extorsiones y secuestros a transeúntes que circulan cotidianamente por esta peligrosa carretera. 
Los diez municipios que cruza la vía tienen las más diversas características: Bolaños, lugar minero por tradición; Totatiche, centro cultural religioso; Mezquitic, lugar indígena; Colotlán, conocido como la capital mundial del piteado, y otros que comparten características y tradiciones como San Martín de Bolaños, Chimaltitan, Villa Guerrero, Santa María de los Ángeles, Huejúcar y Huejuquilla. También, hay productores de artesanías y cultivos tradicionales.

Esta región permanece en silencio ante la marginación y la pobreza. Nunca se queja, lo demuestra su espera latente por un camino digno que apenas hace dos décadas se construyó, conectando al fin la región con la capital del Estado para intentar acceder a los servicios básicos que un Gobierno pudiera proporcionar. Con esta carretera, llegó la modernidad y los tiempos de traslado se redujeron de seis a tres horas. Se instaló una unidad de servicios regionales y con eso se intenta justificar, por parte de los Gobiernos, el abandono que por décadas sufrieron estos pueblos.

La pobreza en la zona norte del Estado es evidente a simple vista y sus números ayudan a disminuir drásticamente las estadísticas de bienestar de los jaliscienses; con limitadas opciones de trabajo, gran parte de la población vive de las pocas remesas que son enviadas desde los Estados Unidos. Las oportunidades de desarrollo profesional no han llegado todavía. Son pocas las corporaciones que buscan establecerse en el norte del Estado a pesar de la mano de obra casi regalada que se encuentra en este lugar.

Las principales actividades económicas en la región norte son la ganadería y la agricultura, la talabartería a través del bordado de prendas de vestir y las artesanías indígenas. El sector industrial y el de servicios se encuentran muy poco desarrollados, hace algunas décadas la industria minera tuvo un gran auge en algunos municipios, y durante algún tiempo implicó riqueza, aunque en la actualidad está paralizada por la ola de violencia que ha vivido esta región del país en los últimos años y que ha impactado en varios órdenes de la vida productiva y cotidiana de sus habitantes. 


\section{Los niños y jóvenes en la zona norte de Jalisco y el sur de Zacatecas}

La vida de los jóvenes en la región que abarca el norte de Jalisco y el sur de Zacatecas se adapta a la única realidad económica, social y educativa que tienen a su alcance. Aunque las alternativas no son muchas.

Últimamente, han encontrado algunas opciones nuevas que abren sus horizontes y visión: la apertura de bachilleratos tecnológicos y centros de educación superior en comunidades anteriormente olvidadas por los Gobiernos, como el Tecnológico Superior de Tlaltenango, en el sur de Zacatecas, o el Centro Universitario del Norte, en Colotlán, los cuales ofrecen licenciaturas, ingenierías e, incluso, posgrados como buenas opciones para los muchachos. La llegada de profesores desde las capitales de Guadalajara, Aguascalientes, Zacatecas y Ciudad de México, así como otros Estados de la República Mexicana, también brinda modelos novedosos de vida a los jóvenes de la región, que de un modo u otro pueden beneficiarlos. Es gente que aporta visiones diferentes, no necesariamente superiores ni mejores, pero cuando menos distintas a lo que ellos han conocido.

Empero, el acceso a los centros de educación es limitado y están muy lejos de llegar a todas las comunidades y sus jóvenes habitantes, mucho menos a las que se encuentran más enclavadas en los confines de la Sierra Madre Occidental, donde, por cierto, existen mayores reportes de violencia, agresiones, tiroteos y presencia en general del crimen organizado. En las zonas del cañón de Bolaños y Mezquitic, por ejemplo, cuentan con buena parte de población indígena y se ha reportado que cruzan las principales rutas del tráfico de droga a través de brechas y caminos de tierra, desde los Estados del norte del país y la frontera con Estados Unidos, hacia la capital de Jalisco, Aguascalientes y Ciudad de México (Spiller, 2014).

En un dibujo infantil, realizado por un niño de primaria y reportado por la doctora Ma. Teresa Prieto Quezada (2011), se ostenta una pequeña frase redactada por un estudiante de siete años, que revela una realidad que causa preocupación y resulta escalofriante: “Quiero ser Chapito Guzmán para tener dinero y ser famoso. El más buscado. FIN” (Prieto Quezada, 2011, p. 45) 
Bajo esta frase, se encuentra en el dibujo la silueta de un individuo con traje y gorra militar accionando un cuerno de chivo (presuntamente el líder de un poderoso cartel del narcotráfico), rodeado por una gran cantidad de billetes de mil pesos, un automóvil, más bien una camioneta de grandes ruedas, y un avión. Ilustra ampliamente cuál es el ideal de vida y las cosas que admiran buena parte de niños y jóvenes actualmente en México.

Los dibujos de niños de primaria y preescolar de la zona norte de Jalisco describen, sobre todo, escenas de tiroteos, asesinatos e, incluso, masacres de las que ellos han sido testigos presenciales, víctimas o que han escuchado hablar de ellas a los adultos. Aparecen detalles sorprendentes que revelan el amplio conocimiento sobre el tema que tienen los niños (al parecer de primera mano): tanques de guerra, nombres específicos de armas - cuernos de chivo, bazucas, granadas de mano, rifles de alto poder, navajas, etc.—, además, emergen en sus ilustraciones pseudónimos de sicarios, pistoleros y traficantes caídos o desaparecidos en la región, de los cuales los pequeños tienen bastante conocimiento: “La Vaca”, “el Largo”, “el Tarzán”, etc. (2011).

A partir del dibujo de una pequeña niña habitante de esta región, se da cuenta de una aparatosa balacera ocurrida en el 2011, en la parte serrana del municipio de Mezquitic, de la cual muy poco se escuchó hablar en la Ciudad de México y en Guadalajara. Se dice que duró más de 24 horas y se extendió desde el norte de Jalisco hacia Zacatecas y Durango. Las palabras de la niña, redactadas en la parte inferior de su dibujo, donde puede apreciarse un conjunto de aditamentos bélicos de los grupos armados (chalecos antibalas, navajas, R15, pistolas, etc.), hablan por sí solas:

Hace tiempo aquí en Mezquitic hubo una balacera, atacaron con pistolas, navajas, etcétera. Había un poco de sangre, un hombre murió, toda la gente en su casa estaba preocupada, traían sus rosarios para pedirle a Dios que nada malo le pasara a su familia. Los narcos o zetas traían chalecos antibalas para evitar que los policías les tiraran balas. (2011, p. 43) 
La doctora Teresa Prieto encontró que los niños, jóvenes y la gente de la región norte de Jalisco clasificaban el crimen organizado dividiéndolo en "narcos buenos" y "narcos malos". Estos últimos, llamados así por los sujetos de su estudio, miembros del cartel de los Zetas, secuestraban a la gente que no estaba involucrada con su negocio, amedrentaban y extorsionaban a los comerciantes para que les pagaran con tal de no hacerles daño. Esto era lo que se conocía en el caló de la gente de la región como "el cobro de plaza”. Los Zetas poseían el control del tráfico de estupefacientes y otros negocios que les reportaban buenas ganancias: la prostitución, el negocio de la piratería, el cobro de cuotas mensuales a los dueños de bares, comercios y restaurantes (2011).

Los "buenos" son los miembros de un cartel "nuevo", procedente del norte del país: de Tamaulipas, Tijuana y Sinaloa, que en los últimos años inició una sangrienta guerra para tratar de desplazar a los primeros y quedarse con el control comercial de la región. Supuestamente, los "narcos buenos", según las palabras de los niños y jóvenes entrevistados por la doctora Prieto, son muy amables y solo realizan retenes en los caminos para verificar que los conductores y transeúntes no sean parte de un grupo criminal opositor.

Aparentemente, "los buenos" no son tan "buenos", ni tan "nuevos”. Son casi los mismos, pero en nueva presentación. Originalmente, quien tenía el control del tráfico de drogas en la zona era el llamado Cartel de Sinaloa, liderado por el Chapo Guzmán (Spiller, 2014). Tras el inicio de la guerra del expresidente Felipe Calderón contra el crimen organizado, los carteles tradicionales como el de Sinaloa se desestabilizaron y perdieron posiciones comerciales, lo que permitió la entrada de nuevos grupos deseosos de apoderarse del control de las plazas que poseían los primeros, como los Zetas. Estos eran el brazo armado de otro cartel que se asentaba en la década de los ochenta y noventa en el Golfo de México (Spiller, 2014). Al verse, hasta cierto punto, desempleados y al movilizarse el grupo de Sinaloa, entraron a esta región para controlar los espacios dejados por el primer cartel.

La gente del Cartel de Sinaloa regresó al norte de Jalisco y el sur de Zacatecas en los últimos años (2014) para tratar de recuperar sus antiguos lugares de comercialización y cotos de poder. Lograron, de hecho, recobrar bastantes de sus antiguas posiciones. Esto convirtió los caminos 
y las comunidades de esta región bastante inseguras, por quedar en medio del frente de batalla de dos grupos armados en competencia.

Cuando los Zetas entraron a la zona norte de Jalisco a inicios del 2006, asesinaron y desaparecieron a muchas personas que antes trabajaban para los de Sinaloa y se negaron a colaborar con ellos. Con el retorno del primer cartel a la región, nuevos derramamientos de sangre se presentaron, tanto de familias, niños, militares, policías y personas involucrados como de gente que no tenía nada que ver en el asunto (Spiller, 2014).

En las ilustraciones infantiles, obtenidas por el estudio de la doctora Teresa Prieto, se revelan los estragos psicológicos en los niños de esta guerra y sus consecuencias para la vida cotidiana. Alrededor de sus dibujos, los niños escriben mensajes donde refieren que no pueden salir con su familia como antes, debido a los toques de queda y retenes organizados por el crimen organizado. Si la violencia al inicio los asustaba, ahora cada vez más hace parte de su vida cotidiana e, incluso, de sus juegos y sueños. No les queda más remedio que acostumbrarse a ella, ignorarla y hacer como que no existe o, en el peor de los casos, volverse parte.

\section{La fuerte carga emocional de los narcocorridos}

Quien haya visitado alguno de los municipios de la zona norte de Jalisco o el sur de Zacatecas ha podido notar casi inmediatamente la música a todo volumen producida por las camionetas y vehículos de muchos de sus habitantes mientras circulaban alrededor de los quioscos de los pueblos y pequeñas ciudades, por sus calles y plazas. En algunos de los municipios pertenecientes a estas regiones, llegó a presentarse la iniciativa de multar a quien escuchara la música a un volumen demasiado elevado por alterar la paz pública. Sin embargo, siempre fracasaron todas esas propuestas y la gente se aferró a sus costumbres más arraigadas para divertirse y procurar recrearse.

Mucha de esa música que se escucha actualmente en aquella región así como en otras de las zonas conflictivas de México es el narcocorrido. Es escuchada tanto por personas vinculadas con el crimen organizado como, en su gran mayoría, por individuos que no tienen 
absolutamente ningún nexo con ellas, lo hacen por mero gusto, moda, emoción o admiración hacia sicarios y traficantes. También, este gusto se propicia por la ausencia de modelos culturales más enriquecedores para el desarrollo humano.

Tradicionalmente, la música que se escuchaba en esta región, con sus excepciones, era la denominada "norteña", que relataba las tribulaciones de los migrantes al intentar cruzar la frontera con los Estados Unidos. Contaban sus amores fallidos, fracasos, idas y vueltas hacia el país vecino a través del río Bravo o el desierto.

Los corridos eran parte fundamental de la corriente musical norteña, la cual describía aventuras, andanzas, peripecias y trágicos finales de diversos personajes idealizados por el imaginario popular. Desde la época de los Dorados de Francisco Villa, probablemente desde antes de la Revolución mexicana, se componían corridos para alabar a algún centauro, líder revolucionario, rebelde, bandolero o burlador de la justicia. También para ridiculizar o abuchear a los enemigos del pueblo; como ejemplo tenemos La Cucaracha, bastante conocida y compuesta por los músicos villistas para burlarse de Victoriano Huerta.

En algún momento del desarrollo histórico de la cultura del norte de México, los corridos y la música norteña comenzaron a introducir temas y personajes procedentes del crimen organizado, particularmente del relacionado con la producción y el tráfico de estupefacientes. Se dice que esto inició con la aparición del corrido Camelia la Tejana, aunque es posible que el fenómeno sea más viejo.

Con los quiebres de la política del Estado mexicano, las crisis económicas y las épocas de carencia, grupos del narcotráfico comenzaron a llenar el vacío dejado por el errático actuar de los Gobiernos. De hecho, se apoderaron del control de la política y la vida social en muchas regiones. Entonces, surgió el narcocorrido, dedicado a relatar los sucesos relacionados con los carteles del narcotráfico y alabar a sus capos y dirigentes:

En un contexto en que la industria musical atraviesa por su más severa crisis y las marcas para lograr discos de oro y de platino por ventas disminuyen de manera inversamente proporcional al incremento de posibles compradores, la llamada música regional 
mexicana es una de las pocas categorías que continúan siendo altamente rentables. Un muy importante elemento de esta corriente es el narcocorrido. A pesar de presiones moralizadoras, los grupos continúan grabando este tipo de corridos e interpretándolos en sus presentaciones. Desde el punto de vista legal va a ser muy difícil que haya sincronía binacional en los esfuerzos prohibitivos y la legislación de sólo uno de los dos países nunca va a poder detener un fenómeno que es cardinalmente fronterizo, siempre habrá o bien alguna estación de música mexicana en Estados Unidos que los toque y cuya señal llegue al lado mexicano, o desde éste, una estación que alcance a los radioescuchas en Estados Unidos. Y es que el narcocorrido no es sino una manifestación cantada y contada de un marco de violencia y desasosiego que priva en el país. (Ramírez-Pimienta, 2011, p. 21)

De acuerdo con el especialista en literatura y cultura popular Juan Carlos Ramírez-Pimienta, de la Universidad de San Diego, el narcocorrido aparece cuando las políticas gubernamentales dejan un hueco debido a su actuar errático e irresponsable. En las peores épocas de crisis económica, política y social, es cuando emerge como una válvula de escape del inconsciente popular este tipo de música.

La doctora Ma. Teresa Prieto, en su estudio realizado con niños de la zona norte de Jalisco, encontró que un 52 \% de sus sujetos de estudio no escuchaban nunca ni habían oído hablar de este tipo de música. Pero el otro 48 \% no solo la conocían, sino que la escuchaban a diario e incluso se emocionaban con ella y sabían de antemano a quién estaba dirigida y compuesta. Los sujetos investigados por ella señalaron no experimentar miedo ni temor cuando escuchaban esta música:

Cuando se les preguntó a los niños, qué sentían cuando los escuchaban, el $41 \%$ señalaban que sentían mucha emoción. Y el 4 $\%$ que les fluía la adrenalina. Este dato nos debe preocupar por la implicación que tiene el emocionarse al escuchar una canción como estas para estimular y ejercer una acción similar a las que plantean las letras.

\section{$[\ldots]$.}


Al preguntarse si sienten miedo al escuchar esta música, señala el $96 \%$ que no, esta es otra respuesta que nos inquieta... (Prieto Quezada, 2011, p. 53)

Llama la atención que casi la mitad de los sujetos de su muestra no solo conocen de memoria los intérpretes, sino las letras completas de los narcocorridos. Y refieren que no experimentan miedo al escuchar esta música, sino emoción y excitación.

Muchas iniciativas surgieron a partir del año 2006, cuando la guerra contra el narcotráfico del Gobierno calderonista estaba en su clímax, para tratar de censurar e, incluso, prohibir que se presentara este género musical en radiodifusoras y canales televisivos. Empero, tal como señala el especialista Ramírez-Pimienta, el fenómeno del narcocorrido es un problema binacional, de naturaleza fronteriza. El narcocorrido es escuchado tanto en la frontera sur de los Estados Unidos como en el lado norte de México, incluso en todo el país. Si es censurado en un lado del río Bravo, todavía se puede tener acceso a él por medio de las estaciones del país vecino.

Luego, están las estaciones de radio por internet, los canales de videos de redes sociales y los blogs y webs musicales independientes, sobre los cuales no se tiene ningún control. Muchos de ellos no están ni siquiera en México, pero son administrados por mexicanos o por gente que conoce, gusta y difunde los narcocorridos y otro tipo de música violenta mexicana.

Los grupos musicales han hecho caso omiso de las prohibiciones gubernamentales y continúan tocando narcocorridos en sus conciertos. Los adultos los escuchan por gusto, para presumir y ostentar una imagen falsa de poder y virilidad, o por ignorancia. Y los niños se aprenden e interiorizan estas canciones tan solo porque sus padres, tutores y profesores no poseen tampoco o no buscan ninguna otra opción de cultura musical.

Lo más preocupante del asunto es la cotidianización de la violencia a través de la música. Resulta natural para niños y jóvenes oír hablar de asesinatos, armas y estupefacientes y cantar sus versos a diario, como si nada, sin ningún filtro moral por parte de los adultos. 
El narcocorrido no consiste más que en un síntoma de una problemática mucho más grande, la cual pretende inútilmente atacarse censurando las estaciones de radio y televisión. Tendría que atenderse la educación musical de los niños desde la formación en el preescolar y la primaria; mostrar que existen otros modelos de cultura, música, lecturas y recreación; que hay cosas con las que niños y adolescentes tienen contacto diariamente, las cuales dañan la mente y el corazón sin que nadie lo perciba.

\section{La adicción al dinero fácil}

Fenómenos como la violencia en las ciudades, los pueblos, el campo, las escuelas; el consumo y tráfico de drogas, y la búsqueda en general del dinero fácil por parte de niños y adolescentes tienen raíces comunes que se hunden en lo profundo de la infancia y la inmadurez de las sociedades y los individuos.

Desde su poderosa trinchera psicoanalítica, el doctor Raúl Páramo Ortega ha equiparado la adicción a los estupefacientes con la adicción al dinero fácil:

Encontramos que una de estas perturbaciones, examinada más detenidamente, presenta características que en nuestra opinión justifican el término de adicción. Se puede observar que los mecanismos psicológicos que se encuentran en el fondo de la adicción a la cocaína, por ejemplo, son fundamentalmente los mismos que en la adicción al dinero. Es más, unos van de la mano de los otros... (Páramo Ortega, 2006)

Según este psicoanalista, filósofo y teórico social, debe observarse la angustia latente a cualquier adicción: adicción a los juegos de azar, a los estupefacientes, al alcohol, a la violencia, etc. La misma angustia primigenia vivida en estas se encuentra presente en la adicción al dinero fácil o a las posesiones ajenas, experimentada por ladrones, traficantes, extorsionadores, violadores, atracadores, entre otros. El paciente padece una inquietud que nada puede llenar y que controla todo su actuar. Una probada de una droga, la que sea que venga al caso, tan solo calmará momentáneamente las ansias autodestructivas del sujeto. 
Esto producirá una saciedad muy relativa y momentánea, seguida de la consiguiente culpa, depresión y el ímpetu correspondiente a un nuevo periodo de ansiedad y la búsqueda reiterada del tranquilizante psicológico que proporciona la droga.

Dicha angustia, de acuerdo con el doctor Páramo, tiene sus orígenes en la infancia de los sujetos y sus comunidades. Se encuentra relacionada con el periodo edípico, entre los 2 y 6 años, aproximadamente. En México, quizá sea mucho más prolongado.

Esto se relaciona con el debilitamiento de las figuras paternas y masculinas en la cultura y la sociedad de las últimas décadas en nuestro país, aunado al fortalecimiento, a veces no crítico, de la imagen de la mujer. Esto da como resultado familias y comunidades con padres debilitados, ausentes, castrados, borrados e incluso debilitados por completo, donde cada vez más mujeres, madres y abuelas se hacen responsables tanto de la manutención como del cuidado y la educación de los hijos, sin mucha o ninguna colaboración de figuras masculinas de respeto:

Las funciones de amortiguar la frustración, tanto como la de estimular el Yo, las encontramos en ocasión del uso del dinero en las "compras compulsivas"; esto es, en las "compras tras la frustración”. O ante la angustia y en la psicología del hurto. (Páramo Ortega, 2006, p. 259)

La misión de la figura masculina es imponer ciertos límites y topes al desarrollo del Yo del niño en su formación; es decir, reprimir sanamente, regañar, llamar la atención y enseñar a veces de forma hasta cierto punto dura lo que está bien y lo que está mal. La madre o la imagen femenina también demarca límites al niño, hasta cierto punto y en parte, porque principalmente se encarga de satisfacer, proveer y nutrir emocional y biológicamente al niño.

Al ver borrado o nulificado el papel del padre, y esto como un fenómeno cada vez más generalizado, la madre no puede por sí sola imponer y enseñar a los hijos todos los límites y reglas. En muchas ocasiones, sin el apoyo de una figura masculina complementaria, solo se limita a complacer y satisfacer sin freno alguno a los infantes. 
Al no ser frustrado sanamente, el individuo se desarrolla sin que desaparezca la angustia edípica relacionada con la satisfacción oral y sexual infantil que proveía la madre. Permanecerá toda su vida gobernado por sus impulsos orales e infantiloides sin control: comer, tomar objetos a placer, aunque no sean suyos, beber e introducirse sustancias enervantes sin parar. Obtendrá lo que desea, pero a partir de esfuerzos por manipular, forzar, encapricharse, robar, hacer trampa, seducir, mentir, etc., como lo hacía de niño con su madre.

El periodista y sociólogo Alberto Spiller retoma la historia de vida de un joven quien en la búsqueda del dinero fácil, se enroló con un cartel del narcotráfico en Guadalajara, desde donde fue enviado a Holanda como "mula" o bodega humana transportadora de cocaína en sus intestinos (Spiller, 2014a). Estando en Róterdam, es testigo de cómo dos de sus compañeros traficantes mexicanos mueren al estallarles en las entrañas las cápsulas contenedoras de droga.

“[...] a uno de ellos lo dejaron tirado en la calle...”, expresó el joven a su entrevistador, oculto y tras el anonimato, escondiéndose de sus perseguidores, quienes antes eran sus amigos y compañeros de delito (Spiller, 2014a).

Al verse obligado a vivir de la caridad e imposibilitado de vender la droga en el extranjero al precio exigido por sus jefes narcos, empleó sus únicas ganancias en regresar a México, donde vive escondido desde entonces, pues sus excompañeros traficantes dicen que les debe varios millones de pesos y no cesan de asediarlo.

Entonces, surge el cuestionamiento acerca de los motivos que impelen a los adolescentes y niños a enfilarse en los grupos delincuenciales, a ingresar a un mundo del que se sabe que no existe el regreso.

La hipótesis de la angustia de la que habla el doctor Páramo, que solo puede ser tranquilizada mediante la ingesta de la droga, por la obtención y dilapidación del dinero fácil, ajeno u obtenido por medios ilícitos, no resulta nada descabellada.

Los niños que fueron frustrados en los primeros años del periodo edípico permanecerán toda su vida experimentando la frustración y la angustia relacionadas con las adicciones, la cuales no pueden ser saciadas más que con el consumo de la droga, ya sea obtenida con 
dinero fácil, arrebatado a otros mediante amenazas, manipulaciones, u otros métodos.

Siguiendo al doctor Páramo, los entornos de violencia, crimen, drogadicción y narcotráfico podrían catalogarse como contextos infantilizados o subdesarrollados emocionalmente, en los que los actores de la violencia y el crimen fueron poco frustrados o aprendieron casi ningún límite emocional durante la infancia. 


\section{Bibliografía}

Páramo Ortega, R. (2006). El psicoanálisis y lo social. En Ensayos Transversales. Guadalajara, México: Universidad de Guadalajara.

Prieto Quezada, M. T. (2011). Niñez alterada. Una niñez mediada por la música. Guadalajara: Prometeo.

Ramírez Pimienta, J. (2011). Cantar a los narcos. Voces y versos del narcocorrido. México: Planeta.

Spiller, A. (2014a). A la sombra del narco. Revista Replicante. Guadalajara, México. Recuperado de: http://revistareplicante.com/a-la-sombra-del-narco/

Spiller, A. (2014b). La ilusión del narco. Revista Replicante. Guadalajara, México. Recuperado de: http://revistareplicante.com/la-ilusion-del-narco/ 